\title{
A INSTITUCIONALIDADE DA EXTENSÃO UNIVERSITÁRIA A PARTIR DO SIGAA: PERSPECTIVA DOS DOCENTES DA UFPB
}

http://dx.doi.org/10.5902/2318133855380

\author{
Luiz Daniel Costa Falcão' \\ Renato Arcúrio Milagre ${ }^{2}$ \\ Edineide Jezine ${ }^{3}$
}

\begin{abstract}
Resumo
Neste texto avalia-se a institucionalidade da extensão universitária a partir do Sistema Integrado de Gestão e Atividades Acadêmicas - Sigaa - da Universidade Federal da Paraíba - UFPB. A análise partiu do seguinte questionamento: o Sigaa é satisfatório enquanto instrumento de registro das ações de extensão desenvolvidas na UFPB? Os objetivos foram avaliar as opiniões e a aceitabilidade dos professores e assessores de extensão sobre o módulo e identificar fatores que poderiam contribuir para aperfeiçoar o sistema. Concluiu-se que o Sigaa permitiu qualificar o registro das ações extensionistas desenvolvidas na UFPB, assim como contribuiu para a institucionalidade da extensão universitária e sua consolidação enquanto função acadêmica e social.
\end{abstract}

Palavras-chave: extensão universitária; institucionalização; sistema integrado de gestão.

\section{THE INSTITUTIONALITY OF UNIVERSITY EXTENSION FROM THE SIGAA: PERSPECTIVE OF PROFESSORS OF THE UFPB}

\begin{abstract}
This research focused on the institutionality of university extension from the Integrated Management and Academic Activities System - Sigaa -, under perspective of extensionists professors of Federal University of Paraíba. This analysis was based on the following question: is Sigaa satisfactory as an instrument for recording extension actions developed at UFPB? To answer that, the research aimed: to evaluate the opinions and acceptability of professors and extension advisors about the module and identify factors that can contribute to improving the system. The module allowed a great advance in the registration of extension actions developed at UFPB, contributing to the institutionalization of university extension and its consolidation as an academic and social function.
\end{abstract}

Key-words: university extension; institutionalization; integrated management system.

\footnotetext{
1 Universidade Federal da Paraíba, Brasil. E-mail: danielfalcao5@hotmail.com.

2 Universidade Federal da Paraíba, Brasil. E-mail: renato17@hotmail.com.

3 Universidade Federal da Paraíba, Brasil. E-mail: edjezine@gmail.com. 


\section{Introdução}

o mundo globalizado em contínua mudança, a universidade é vista como um locus de possibilidade de inclusão social a partir de conhecimento e competências desenvolvidas pois, historicamente, as universidades são instituições responsáveis pela geração de conhecimento e sua aplicação com vistas à transformação da sociedade (Ribeiro, 2019).

$\mathrm{Na}$ realização da missão de produção do conhecimento a universidade sustenta-se sobre três pilares: o ensino, a pesquisa e a extensão, esta última emergindo a partir das demandas da sociedade em suas necessidades de formação, frente aos processos de exclusão social de sujeitos que não possuem a oportunidade do acesso ao conhecimento.

No Brasil o processo de institucionalização da extensão universitária tem sua maior expressão no século 20, ganhando mais força após a década de 1980 com a criação do Fórum de Pró-Reitores de Extensão das Universidades Públicas Brasileiras. O Fórum, como uma instância da sociedade civil, atua com a missão de promover discussões e proposições para a institucionalização da extensão universitária em instituições públicas de educação superior, como um processo educativo, articulador entre ensino e pesquisa sob a perspectiva interdisciplinar, tornando-se expressão mais evidente da função social da universidade.

Dentre as pautas deste fórum está o registro das ações de extensão como forma de contribuir para o gerenciamento das atividades e institucionalização da extensão universitária como função acadêmica da universidade (Jezine, 2006). Na Universidade Federal da Paraíba buscou-se registrar de forma sistemática e organizada as ações de extensão a partir da década de 1990, para isso, utilizou o sistema Banco de Dados de Extensão - Bandex -, Sistema de Informação e Gestão de Projetos - Sigproj - e, atualmente, o Sistema Integrado de Gestão e Atividades Acadêmicas - Sigaa - cujo módulo de extensão foi implantado em 2017.

Diante da recente implantação e do uso do módulo de extensão, ainda em fase de adaptação pela comunidade universitária, emergiu o questionamento: o Sigaa é satisfatório e eficiente enquanto instrumento de registro das ações de extensão desenvolvidas na UFPB? Sob este questionamento, o foco de análise permeia a avaliação da institucionalidade da extensão universitária a partir do registro de suas ações pelo Sigaa. Nesta perspectiva buscou-se analisar a aceitabilidade dos professores extensionistas e assessores de extensão sobre o módulo, a fim de reconhecer quais fatores poderiam contribuir, do ponto de vista docente, para aperfeiçoar o sistema.

A metodologia seguiu um caráter descritivo e analítico a partir da perspectiva da pesquisa exploratória. Quanto aos procedimentos metodológicos foi realizada a revisão da literatura e pesquisa documental, buscando reconhecer os principais eventos que registram suas ações de intervenção. Em seguida buscou-se conhecer a percepção sobre a aceitabilidade dos docentes extensionistas e assessores de extensão com relação ao módulo de extensão do Sigaa. A coleta de dados ocorreu mediante a aplicação de um 
instrumento, elaborado sob o formato de Escala do Tipo Likert ${ }^{4}$, junto aos docentes coordenadores de ações de extensão. Para a elaboração da referida escala foram apresentadas sentenças ou questões sobre o sistema, focadas nas funções mais utilizadas por esses usuários, como as etapas de submissão de propostas de ação; abertura e gerenciamento de inscrições para cursos e eventos; preenchimento e envio de relatórios e a certificação. Adicionalmente foram realizadas entrevistas com os assessores de extensão de cada centro acadêmico da UFPB.

\section{A extensão universitária e o registro de suas ações na UFPB}

A UFPB foi criada em 1955 e federalizada em 1960, quando se iniciou o processo de expansão. O processo de institucionalização da extensão teve seu período decisivo nos anos 1990, quando o Consepe aprovou a resolução n. 09/93, pela qual se regulamentou as atividades de extensão. Este documento expressa a extensão como uma atividade equivalente ao ensino e a pesquisa e recomenda tratamento igualitário por parte dos centros de ensino e departamentos, com a disponibilidade de recursos financeiros; programação das atividades; distribuição de encargos docentes e a ponderação para efeito da avaliação funcional do docente, atendendo as recomendações formalizadas, como uma função acadêmica da universidade pelo Forproex/Nacional, em sua primeira reunião em 1987 "com três pontos de pauta: conceito de extensão; institucionalidade e financiamento da extensão" (Jezine, 2006).

$\mathrm{Na}$ resolução n. 09/1993 foram elencadas diversas atividades de extensão e foi atribuída à Pró-Reitoria de Extensão e Assuntos Comunitários - Prac -, hoje Pró-Reitoria de Extensão - Proex -, a coordenação da política, e aos centros de ensino a coordenação e o acompanhamento das atividades de extensão. $O$ documento prevê também a criação do Comitê Assessor de Extensão, cuja função é assessorar a Prac na elaboração da política e propor critérios de avaliação das atividades de extensão. Essa resolução representou o primeiro passo para a normatização da extensão universitária na UFPB, contribuindo para o crescimento e fortalecimento desta prática na instituição.

Além dos preceitos legais estabelecidos na década de 1990 os trabalhos executados nessa época foram de crucial importância para a institucionalização da extensão na UFPB. Serrano (2012) destaca várias atividades como os projetos de pesquisa e extensão Saúde do Trabalhador - Ceresat $^{5}$ (1988); Projeto Zé Peão ${ }^{6}(1990)$; Programa Interdisciplinar de Ação Comunitária - $\operatorname{Piac}^{7}(1990)$ e outros.

\footnotetext{
${ }^{4}$ Foi desenvolvida pelo cientista Rensis Likert entre 1946 e 1970 e é utilizada desde então para se medir a aceitabilidade de determinado produto ou serviço nas mais diversas áreas. Insere-se num conjunto de escalas de autorrelato, nas quais o respondente avalia algo com base na sua opinião particular. Ao respondê-la, o indivíduo afirma seu grau de concordância ou discordância sobre as sentenças apresentadas escolhendo um ponto numa escala com cinco gradações, as mais comuns são: concordo muito, concordo, neutro/indiferente, discordo e discordo muito (Aguiar et al., 2011).

${ }^{5} \mathrm{O}$ Ceresat tem como objetivo realizar pesquisas, formação e atenção à saúde, bem como consultorias no campo da saúde do trabalhador, em busca de contribuir para a construção da política de saúde do trabalhador na Paraíba.

${ }^{6}$ Pelo Projeto Escola Zé Peão realiza-se ações de alfabetização e educação continuada para operários da construção civil.

7 O Piac, pelo Estágio de Vivência em Comunidade e do Estágio Nacional de Extensão em Comunidade, entre outras ações, se destaca por proporcionar para estudantes do Brasil e do mundo vivências dentro das comunidades, trazendo para o aluno a oportunidade de aprender pela experiência.

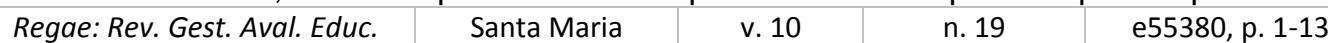


A institucionalização da extensão, numa perspectiva acadêmica, foi estimulada a partir da publicação dos trabalhos desenvolvidos em projetos e ou programas, com a criação da Revista de Extensão, inicialmente impressa, mas que depois passou a ser a Revista Eletrônica Extensão Cidadã $^{8}$ e a publicação da Série Extensão, em que os relatos sobre as ações de extensão ganhavam mais expressividade. Segundo Moraes (2019)

"outra coisa interessante foi a Série Extensão, onde foram publicados 25 livros com temas diversos. Na época do Professor Ivan eu era coordenador no Nuppo e nós conseguimos publicar três volumes, eram justamente os Contadores de Histórias, que publicamos no município de Guarabira, Patos e Catolé do Rocha."

O objetivo dos mecanismos de divulgação era, para além do registro das ações, tornar a extensão uma atividade acadêmica, na medida em que os coordenadores relatavam seus projetos em um canal de difusão científica. Além do registro das ações em sua dimensão acadêmica buscou-se dar visibilidade a extensão universitária por meio do Programa de Bolsa de Extensão - Probex -, criado pela resolução do Consepe n. 76/97, e o Prêmio Novos Autores Paraibanos, iniciativas importantes para a extensão na UFPB.

$\mathrm{Na}$ década de 1990 outro fato importante foi a implantação do Bandex, primeiro sistema de registro das atividades de extensão e transferência de informações da UFPB. O Bandex começou a funcionar experimentalmente em 1994 e foi institucionalizado em 1999 pela resolução n. 55/99. Esse sistema de registro surgiu a partir da necessidade de melhorar e sistematizar as atividades de extensão, tendo sido importante naquele momento em razão da necessidade de dimensionar e construir o perfil da extensão na universidade (Serrano, 2012). Com o Bandex buscou-se identificar e registrar os projetos de extensão desenvolvidos nos campi da UFPB. A utilização desse sistema fortaleceu substancialmente a extensão como função social da universidade.

A resolução n. 09/93 foi revogada pela resolução n. 61 de 2014, que regulamentou as atividades de extensão na UFPB. O documento prevê a necessidade de registrar as ações de extensão:

As propostas de ação de extensão [...] devem ser cadastradas no Sistema de Registro de Extensão que estiver em vigor. O proponente deverá encaminhar, também pelo sistema, o relatório final das atividades desenvolvidas, para fins de emissão dos certificados, e para avaliação das políticas de extensão da UFPB. (UFPB, 2014, p. 3)

Torna-se obrigatório o registro uniforme das ações de extensão, o que contribuiu para a gestão das atividades realizadas na diversidade de ações. Assim, a UFPB, ao possuir a normatização para o registro das ações de extensão, buscou otimizar a adesão da comunidade universitária à prática de registro. Em 2006 a UFPB substituiu o Bandex pela base de dados da UFMG/Siex, e, posteriormente, para o Siex/Brasil, uma versão

8 Desativada no ano de 2010. Até então funcionava como um canal para a democratização do conhecimento produzido a partir da experiência de extensão universitária da UFPB, além da divulgação de artigos elaborados com base na produção acadêmica gerada pelos projetos de extensão.

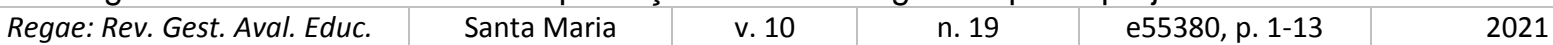


atualizada pela Universidade de Mato Grosso do Sul, que toma o modelo do perfil nacional a partir da parceria com o MEC, adotando a nominação de Sistema de Informação e Gestão de - Sigproj.

Como o Sigproj era destinado apenas à extensão, havia na UFPB outros sistemas que não se comunicavam entre si, o que gerava, além de problemas gerenciais, diferentes dados de acesso de um mesmo usuário e um expressivo número de demandas para a Superintendência de Tecnologia da Informação da universidade. Diante dessa problemática houve a preocupação por parte da STI em oferecer um serviço padronizado para uma gestão integrada de todas as atividades acadêmicas da universidade e, sobretudo, oferecer aos usuários finais um único meio de acesso, com um padrão visual nas páginas e nos controles existentes, facilitando o uso e a gestão das ações (Araújo, 2013).

Com este objetivo, em 2010, a UFPB adotou o Sistema Integrado de Gestão - SIG desenvolvido pela Universidade Federal do Rio Grande do Norte. Os SIGs "formam um conjunto de sistemas cuja função é administrar informações e procedimentos de diferentes áreas funcionais, como recursos humanos, patrimônio, administrativo e acadêmico" (Ufal, 2019).

No caso da UFPB o SIG é constituído de módulos: o Sistema Integrado de Gestão e Recursos Humanos, o Sistema Integrado de Gestão de Patrimônio, Administração e Contratos, o Sistema Integrado de Gestão de Atividades Acadêmicas e o Sistema Integrado de Gestão da Administração e Comunicação. Todos esses módulos são compostos por submódulos com funções específicas, portais e pontos de acesso aos demais sistemas. Desde a sua aquisição a implantação do SIG ocorreu paulatinamente e o módulo de extensão, que faz parte do Sigaa, começou a ser utilizado na UFPB no ano de 2017, em substituição ao Sigproj.

O Sigaa é o módulo mais complexo do SIG, visto que possui sistemas que dão suporte às atividades fins da universidade e o que apresenta a maior quantidade de usuários. Enquanto os demais módulos são administrativos de caráter interno, o Sigaa abrange os sistemas da graduação, pós-graduação e demais sistemas acadêmicos que são acessados pelos alunos da instituição. Assim, o Sigaa disponibiliza portais específicos para: Reitoria, professores, alunos, tutores de ensino a distância, coordenações lato sensu, stricto sensu e de graduação e comissões de avaliação institucional e docente - (Sinfo/UFRN, 2019). Para o professor a ferramenta Sigaa possibilita o preenchimento de notas, frequência, plano de aula, entre outras atividades. Para o discente, promove o acesso às informações das turmas, das disciplinas e outras atividades acadêmicas.

No que tange à extensão a implantação do Sigaa representou uma oportunidade na transparência e acesso às ações promovidas pela UFPB. Com o módulo de extensão qualquer pessoa pode visualizar os cursos oferecidos, os eventos programados, além de conhecer as demais atividades desenvolvidas pela Proex. Outra funcionalidade do Sigaa é a possibilidade de certificação automática das atividades cadastradas. A busca por um registro eficiente das ações de extensão desenvolvidas na instituição está entre as estratégias para o fortalecimento desta prática como função acadêmica da universidade, e 
- Sigaa apresenta-se como um instrumento de execução no campo do registro das atividades de extensão, efetivando a institucionalidade da extensão na perspectiva acadêmica.

Além da gestão das ações destaca-se que com o módulo de extensão do Sigaa a extensão passou a ser gerenciada de modo integrado ao ensino e à pesquisa. Portanto, o Sigaa consolida o processo de institucionalidade da extensão na UFPB.

\section{Perspectiva dos docentes extensionistas da UFPB sobre o módulo de extensão do Sigaa}

A Universidade Federal da Paraíba, conforme explicitado em seus planos de desenvolvimento institucional (UFPB, 2014; UFPB, 2019), vem estabelecendo continuamente medidas para o fortalecimento das atividades gerenciais, de ensino, pesquisa e extensão. No que tange à extensão uma das metas consiste em ampliar e fortalecer as ações de modo a incluir uma maior participação da comunidade universitária.

Com base nos relatórios gerados pelo módulo de extensão do Sigaa, referente às atividades extensionistas registradas no período de 2017 a 2019, pode-se observar o número de ações, bolsas e docentes participantes das ações, conforme a tabela abaixo.

Tabela 1 -

Atividades de extensão desenvolvidas na UFPB, bolsas e docentes participantes nos anos de 2017 a 2019.

\begin{tabular}{l|c|c|c}
\hline \multicolumn{1}{c|}{ Indicadores } & 2017 & 2018 & 2019 \\
\hline Ações & 1083 & 1445 & 1787 \\
\hline Curso & 125 & 184 & 267 \\
\hline Evento & 120 & 239 & 346 \\
\hline Produto & 10 & 10 & 21 \\
\hline Programa & 8 & 14 & 12 \\
\hline Projeto & 820 & 998 & 1141 \\
\hline Bolsas & 616 & 730 & 730 \\
\hline Docentes & 1146 & 1347 & 1353 \\
\hline
\end{tabular}

Fonte: Sigaa (UFPB, 2019)

Constata-se um crescimento no número de ações registradas pelo módulo de extensão do Sigaa. Esse aumento revela que uma das metas para a extensão na UFPB, estabelecida no PDI 2014-2018, foi alcançada. No documento objetivava-se ampliar as ações de extensão, com ênfase na ampliação do número de projetos (UFPB, 2014). Vale mencionar que o aumento não ocorreu apenas no número de projetos, mas também no total de cursos e eventos, favorecendo o aumento na disponibilidade de bolsas para os estudantes e ampliando a participação discente e docente na prática da extensão universitária. 
Dentre os docentes extensionistas 733 professores possuíam a função de coordenador de ação de extensão no momento de realização da pesquisa de campo e foram convidados a responder sobre o módulo de extensão do Sigaa por meio do instrumento de coleta de dados, elaborado sob o modelo da Escala de Likert. As proposições foram elaboradas visando a aferir a opinião dos respondentes sobre 0 módulo de extensão do Sigaa, enquanto instrumento de registro da extensão na UFPB, de modo geral, como também sobre as funcionalidades específicas do sistema. Para tal, foram elaboradas sentenças envolvendo as etapas de preenchimento de novas propostas de ação, de análise e envio de relatórios, de gerenciamento de cursos e eventos e a emissão de certificados.

Com base em cada uma das sentenças disponibilizadas os respondentes poderiam marcar apenas uma opção entre as cinco respostas: discordo totalmente; discordo parcialmente; não discordo e nem concordo; concordo parcialmente; e concordo totalmente. Para cada uma das respostas foi atribuído um valor de 1 a 5 , respectivamente, e a aceitabilidade do sistema foi medida pela soma dos valores de todas as respostas.

A escala foi estruturada com oito sentenças, assim, o valor máximo (- concordância total com os itens - que um indivíduo poderia apresentar era 40 e o valor médio era 24 pontos. Portanto, com base na pontuação de cada resposta e no número de questões criou-se uma classificação em três partes: inferior a 24 pontos: aceitabilidade negativa; igual a 24 pontos: aceitabilidade neutra; e superior a 24 pontos: aceitabilidade positiva. A partir da análise dos scores chegou-se ao indicador da aceitabilidade geral do módulo de extensão do Sigaa.

A análise de aceitabilidade do sistema também foi feita mediante entrevistas aos assessores de extensão, em sua maioria docentes, que exercem uma função articuladora entre o seu centro acadêmico e a Pró-Reitoria de Extensão. Esse estudo, portanto, utilizou-se de uma amostragem não-probabilística e a amostra utilizada foi por conveniência (Oliveira, 2011), uma vez que incluiu todos os docentes coordenadores de ação e assessores de extensão que aceitaram participar da pesquisa. Após convite, um total de 107 docentes extensionistas e nove assessores de extensão responderam a escala disponibilizada.

Dos coordenadores de ação de extensão que responderam o instrumento de coleta de dados, um total de $71,03 \%$ apresentaram pontuação superior a 24 pontos, indicando uma aceitabilidade positiva com relação ao módulo de extensão do Sigaa, ao passo que 28,97\% apresentaram pontuação inferior a 24 pontos, o que representa uma aceitabilidade negativa do sistema de registro utilizado. Em posse dos dados apresentados constata-se que o módulo de extensão do Sigaa é bem aceito pelo corpo docente que realiza ações de extensão na UFPB.

Relatos dos assessores de extensão corroboraram com a opinião dos docentes em geral. Para todos o sistema é bem aceito e apresenta muitos pontos positivos. O primeiro ponto a ser destacado foi o fato de o módulo fazer parte de um sistema integrado de gestão, o qual gerencia tanto atividades de extensão como atividades de pesquisa e ensino, dentre outras funcionalidades, isso possibilita ao docente compilar mais facilmente as suas atividades, como expressa a fala a seguir: "Como docente, acho que temos uma 
ferramenta boa, pois podemos concentrar ações tanto de ensino, pesquisa e extensão numa ferramenta só, o que é muito bom para progressões ou qualquer outra coisa, pois emitimos essas informações como relatório e está tudo lá" (assessor 08).

Além dessa possibilidade, gerenciar as ações de extensão no mesmo sistema de ensino e pesquisa, reflete a valorização da extensão enquanto um dos pilares da universidade, integra a prática extensionista à vivência universitária, contribuindo para a institucionalização. Outro ponto positivo do módulo, destacado pelos entrevistados é a interrelação que se estabelece entre a assessoria do centro de ensino e a Proex, o que faz da extensão um trabalho pedagógico de acompanhamento dos seus processos e resultados:

A assessoria tem como acompanhar os projetos que foram submetidos à avaliação e aqueles que se mantiveram, seja como Probex, Fluex ou UFPB no seu município ficam disponibilizados, o que permite um acompanhamento e conhecimento dos projetos, da equipe, além disso favorece agilidade e transparência pra que toda a comunidade tenha acesso. O módulo é uma ferramenta imprescindível para o acompanhamento e execução dos projetos por parte da equipe organizadora das ações. (Assessor 05)

Quando se busca avaliar a praticidade do módulo o assessor de extensão assinala que o mesmo facilita o acompanhamento do processo por parte do proponente da ação, de modo que a responsabilidade do preenchimento da proposta fica a seu critério, podendo editar e reeditar:

Eu tive muita facilidade com o SIGGA, é uma ferramenta importante pra quem está na assessoria, pois tira a sobrecarga, contanto que os professores se rendam ao sistema [...]. São muitos detalhes que para quem tem mais idade ou menos contato com tecnologia fica mais difícil, mas quando vão na assessoria a primeira vez, fica mais fácil. A frequência de uso do Sigaa facilita o aprendizado, pois no Sigproj só submetia a ação e depois o relatório final, no Sigaa mudamos a equipe, por exemplo. $O$ Sigaa é interessante porque divide a responsabilidade, por exemplo, no edital diz que a responsabilidade da carga horária dos membros da equipe é de quem cadastrou a ação. Eu sou fã do Sigaa. (Assessor 04)

No Sigaa o proponente das ações alimenta o sistema com informações pertinentes à proposta e, dependendo do edital, os próprios professores a avaliam, a exemplo do Probex. O gerenciamento das ações aprovadas é feito pelo coordenador da ação com o auxílio da Proex e do assessor de extensão. O modo como são submetidas as propostas foi considerado com boa funcionalidade, visto que o processo facilita as etapas subsequentes das ações de extensão, como o seu gerenciamento e emissão de certificados:

"Em relação ao módulo de extensão do Sigaa, considero de grande importância todos os itens e informações que são por este solicitadas na organização de projetos, contribuindo com a celeridade nos processos de edital, seleção, avaliação, gestão, monitoramento e finalização das ações, já gerando certificação para os participantes e coordenadores, além de possibilitar o acompanhamento por período, de ações já realizadas." (Assessor 07) 
Além das sentenças elaboradas no formato de Escala do Tipo Likert foi solicitado aos professores que eles relacionassem os pontos positivos e negativos do módulo, além de sugestões de melhorias. A certificação digital foi considerada o principal avanço do módulo de extensão do Sigaa para mais de $80 \%$ dos docentes extensionistas. Isso porque a emissão de certificados pelo próprio sistema de registro não ocorria nos sistemas utilizados anteriormente pela UFPB. O módulo de extensão do Sigaa passou então a emitir certificados com código de verificação, dispensando o uso de carimbos e assinaturas, garantindo mais agilidade ao processo, como expressa o assessor 05: "Com a certificação há segurança tanto para o propositor da ação como para o participante $e$ isso é um estímulo para todos, uma vez que ao término da ação o certificado já é disponibilizado".

Apesar de ser bem aceito $70,1 \%$ dos docentes coordenadores de extensão junto com todos os assessores entrevistados afirmaram que o módulo precisa ser aperfeiçoado. O gráfico abaixo mostra o percentual de participantes do estudo - professores e assessores de extensão - que apresentaram queixas e sugestões de melhorias em diferentes aspectos do módulo de extensão do Sigaa.

Gráfico 1 -

Percentual de professores que realizaram comentários referentes às diversas funcionalidades do módulo de extensão do Sigaa.

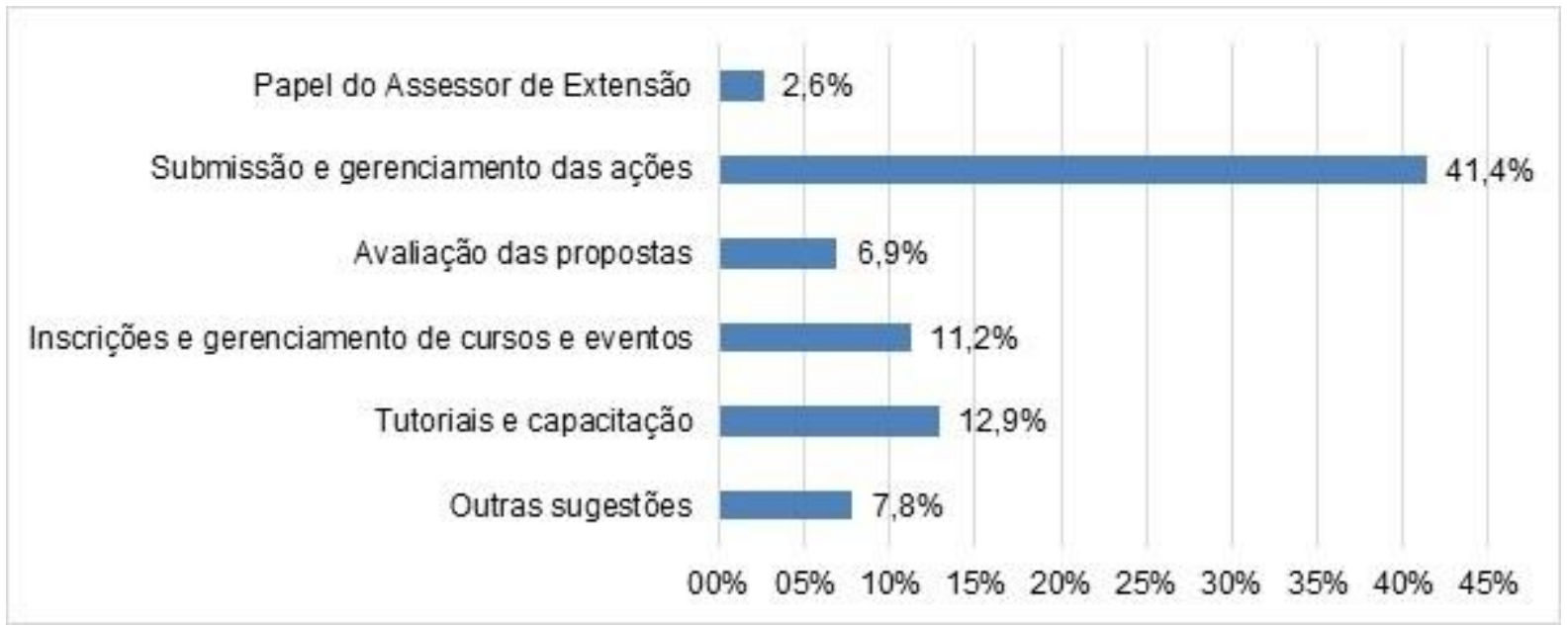

Fonte: autores.

Como mostrado no gráfico 1 a maioria dos participantes $(41,4 \%)$ fizeram críticas quanto a submissão e o gerenciamento das ações feitas no sistema; 11,2\% mencionaram pontos negativos no processo de inscrições e gerenciamento de cursos e eventos, colocando várias sugestões de aperfeiçoamento; 12,9\% enfatizaram a importância de tutoriais e capacitação direcionados aos usuários do sistema; e um percentual menor de participantes elencaram outras sugestões de caráter mais geral, destacando-se a criação de um perfil para o assessor de extensão no módulo, como solicitado por $2,6 \%$ dos indivíduos.

O maior número de posições negativas ao sistema concentrou-se nas etapas de submissão e gerenciamento das ações. Os participantes relataram que o sistema é muito burocrático, pouco intuitivo e difícil de manusear. Na sequência, diversas sugestões foram 
enumeradas para melhorar essa funcionalidade: solicitar menos dados para submissão de uma nova ação vinculada a outra já existente; permitir o preenchimento de atividades e carga horária em uma única tela dentre outras.

Além destas sugestões, destaca-se a proposição com relação ao gerenciamento das ações, a forma de monitoramento das atividades ao longo de sua execução:

"Sendo um módulo de extensão e por conhecer ferramentas similares, considerando que os coordenadores já cadastram os objetivos, atividades, executores e carga horária, considerando que toda informação já está no sistema, acho extremamente relevante e necessário expandir o módulo para que, ao ser registrada uma atividade pelo coordenador, os voluntários e bolsistas designados para a atividade no projeto, possam acessar e preencher o porcentual que já foi executado para a atividade." (Professor 09)

Ainda, segundo o mesmo professor, a expansão do sistema permitirá:

"1) O acompanhamento dinâmico e em tempo real das atividades pelo coordenador do projeto; 2) A comparação entre planejado e executado pelo coordenador do projeto; 3) Gerar gráfico de Gantt para compor relatórios de extensão; 4) Acompanhamento das atividades de cada projeto/coordenador pelos assessores de extensão, possibilitando intervenção e verificação durante o projeto e não somente verificação por um relatório final; 5) Acompanhamento das atividades de cada projeto/coordenador pela Pró-Reitoria de Extensão, possibilitando conhecer por coordenador/projeto/departamento/centro as atividades propostas e executadas, possibilitando identificar problemas de execução no projeto." (Professor 09)

Foi sugerida, ainda, a elaboração de tutoriais em vídeo, explicando como manusear - Sigaa para suas diversas finalidades. Outra sugestão foi a criação de caixas de explicação dentro do sistema, que além de auxiliar no preenchimento, evitaria erros no processo, como colocado por um dos professores:

"Em relação à utilização do menu do sistema, alguns itens não são intuitivos e falta uma caixa de explicação ao lado do campo a ser preenchido, o que facilitaria o trabalho do coordenador, evitando dúvidas no preenchimento e consequentemente a elaboração de ações com informações incorretas e o posterior retrabalho para correção." (Professor 108)

Foi sugerida também a elaboração de um Frequently Asked Questions - FAQ - pelo setor responsável pelo atendimento aos extensionistas e disponibilizadas na página da Proex.

Por fim foi sugerida a realização de capacitações periódicas sobre o sistema de registro e suas atualizações (professor 68), bem como também sobre a extensão universitária em geral "para melhor entendimento sobre a aplicação da extensão como um dos tripés da UFPB de grande importância para a sociedade" (assessor 02). Neste

9 O gráfico ou diagrama de Gantt é uma ferramenta visual usada para ilustrar o avanço das diferentes etapas de um projeto. Foi criado pelo engenheiro americano Henry Gantt no começo do século 20.

Regae: Rev. Gest. Aval. Educ. $\quad$ Santa Maria

v. 10

n. 19 e55380, p. 1-13 2021 
sentido as capacitações são importantes não apenas para melhorar a utilização e aceitabilidade do módulo de extensão do Sigaa, mas também para consolidar o processo de institucionalização da extensão na universidade.

Outras sugestões de caráter mais geral foram feitas por vários professores como: melhorar o layout da página; permitir uma personalização maior no preenchimento das propostas conforme características específicas; permitir o resgate de dados antigos referentes a ações anteriores à implantação do Sigaa; tornar possível a geração de relatórios mais diversificados e indicadores de avaliação.

Com base nos dados apresentados sobre o módulo de extensão do Sigaa percebese que a sua implantação permitiu a institucionalidade da extensão a partir do registro de atividades. Apesar de alguns problemas apresentados pelos usuários, mudanças vêm sendo propostas e implementadas para adaptar o sistema às necessidades dos docentes, discentes e assessores que fazem a extensão na UFPB.

Para os sujeitos da pesquisa o registro das atividades de extensão apresenta-se como uma ação importante para o fortalecimento e a valorização desta prática. De fato, como enfatiza Baudel (2016), uma boa gestão da informação facilita o desempenho da universidade como gestora e pilar estratégico, por meio da sistematização de seus dados. O registro das ações de extensão desenvolvidas garante maior segurança, organização e padronização, além de viabilizar a avaliação e a contabilização da produção extensionista com qualidade.

A partir da avaliação do módulo é possível avaliar a progressão da extensão ao longo dos anos e criar metas e planos de ação para aprimorar o processo de registro, execução e avaliação das atividades de extensão. Portanto, fica claro que a institucionalização da extensão universitária passa pelo registro das atividades de forma sistemática, e que o módulo de extensão do Sigaa vem contribuindo, positivamente, para esse processo na UFPB. E, o fato do módulo ser parte de um sistema integrado de gestão fortalece, ainda a extensão como parte indissociável do ensino e da pesquisa na universidade.

\section{Considerações finais}

O processo de institucionalização da extensão na UFPB, mediante o registro das suas ações no módulo de extensão do Sigaa. O módulo de extensão do Sigaa mostrou-se bem aceito pelos docentes e assessores de extensão. Para a maioria dos participantes cerca de $70 \%$-, o sistema permitiu a informatização dos dados referentes à extensão, especialmente com relação à certificação digital das ações. É possível afirmar que o módulo de extensão do Sigaa tenha contribuído para aumentar a adesão da comunidade universitária ao registro de suas atividades de extensão. Entretanto, aproximadamente o mesmo percentual de indivíduos concorda que o sistema precisa ser melhorado.

Foram elencados alguns pontos negativos e sugestões de melhorias do sistema, que possivelmente possibilitará um aumento na adesão da comunidade universitária, especialmente dos docentes, à prática extensionista e ao registro adequado de suas ações. Um sistema de preenchimento mais prático, além de uma boa publicidade, aumentará a quantidade de registros das ações de extensão. 


\section{Referências}

AGUIAR, Bernardo; CORREIA, Walter; CAMPOS, Fábio. Uso da escala likert na análise de jogos. Arts \& Design Track - Short Papers. SBC - Proceedings of SBGames. X SBGames, Salvador, 2011, p. 1-5.

ARAUJO, Emerson Diego da Costa. Implantação do sistema integrado de gestão (SIG) na UFPB: um estudo de caso. João Pessoa: UFPB, 2013. 108f. Dissertação (Mestrado Profissional - Gestão em Organizações Aprendentes. Universidade Federal da Paraíba.

BAUDEL, Roberta Macedo. Condicionantes e resultados da utilização de um novo sistema de informações gerenciais: um estudo da adoção do SIGProj na extensão da UFPE. Recife-PE: UFPE, 2016. 188f. Dissertação (Mestrado Profissional em Administração). Universidade Federal de Pernambuco.

JEZINE, Edineide. A crise da universidade e o compromisso social da extensão universitária. João Pessoa: UFPB, 2006.

MORAES, José Augusto de. Entrevista concedida a Luiz Daniel Costa Falcão. João Pessoa, 12 dez. 2019.

OLIVEIRA, Maxwell Ferreira de. Metodologia científica: um manual para a realização de pesquisas em Administração. Catalão: UFG, 2011.

PRODANOV, Cleber Cristiano; FREITAS, Ernani Cesar. Metodologia do trabalho científico: métodos e técnicas da pesquisa e do trabalho acadêmico. Novo Hamburgo: Feevale, 2013.

RIBEIRO, Raimunda Maria da Cunha. Universidade pública: mapeamento das políticas de ensino, pesquisa, extensão e inovação. Revista Práxis Educacional, Vitória da Conquista, v. 15, n. 33, 2019, p. 421-443.

SERRANO, Rossana Maria Souto Maior. Avaliação institucional da extensão universitária na UFPB: a regulação e a emancipação. João Pessoa: UFPB, 2012. 196f. Tese (Programa de Pós-Graduação em Educação). Universidade Federal da Paraíba.

SINFO/UFRN. Sistemas institucionais integrados de gestão - SIG. Disponível em https://docs.info.ufrn.br/doku.php. Acesso em 5 jan. 2020.

UFAL. Sistemas institucionais integrados de gestão - SIG. Disponível em http://www.ufal.edu.br/sig/sig. Acesso em 7 jul. 2019.

UFPB. Plano de desenvolvimento institucional 2019-2023. João Pessoa: UFPB, 2019. Disponível em http://www.proplan.ufpb.br/proplan/contents/documentos/pdi/pdi_20192023_posconsuni-1.pdf. Acesso em 15 abr. 2020.

UFPB. Plano de desenvolvimento institucional 2014-2018. João Pessoa: UFPB, 2014. Disponível em http://plone.ufpb.br/cpa/contents/arquivos/pdi-ufpb-2014-2018.pdf/view. Acesso em 12 ago. 2017.

UFPB. Resolução n. 61 de outubro de 2014. Regulamenta as atividades de Extensão da UFPB e dá outras providências. João Pessoa: UFPB, 2014. Disponível em http://plone.ufpb.br/prac/contents/paginas/portaarquivos/resolucao-atividades-deextensao-no-61-2014.pdf. Acesso em 7 jul. 2019.

UFPB. Resolução n. 09 de março de 1993: regulamenta as atividades de Extensão da UFPB e dá outras providências. João Pessoa: UFPB, 1993. Disponível em http://www.cear.ufpb.br/arquivos/resolucoes/Extensao\%20-\%20Resolucao\%2009-93.pdf. Acesso em 7 jul. 2019. 
Luiz Daniel Costa Falcão é auxiliar em administração na Universidade Federal da Paraíba.

Orcid: https://orcid.org/0000-0003-1368-2429.

Endereço: Rua Silvino Chaves, 625 - 58038-420 - João Pessoa - PB - Brasil.

E-mail: danielfalcao5@hotmail.com.

Renato Arcúrio Milagre é administrador no Instituto Federal da Paraíba.

Orcid: https://orcid.org/0000-0003-2571-3819.

Endereço: Rua Santa Catarina de Cássia, 1900 - 58103-772 - Cabedelo - PB - Brasil.

E-mail: renato17@hotmail.com.

Edineide Jezine é professora na Universidade Federal da Paraíba.

Orcid: https://orcid.org/0000-0002-0180-0347.

Endereço: Cidade Universitária, s/n - 58051-900 - João Pessoa - PB - Brasil.

E-mail: edjezine@gmail.com.

Recebido em 26 de setembro de 2020.

Aceito em 16 de dezembro de 2020.

(c) (1) $(9)$ 